\title{
Gentianaceae endémicas del Perú
}

\section{Susy Castillo ${ }^{1}$, Norma Salinas ${ }^{2}$, Blanca León ${ }^{1,3}$ e Isidoro Sánchez ${ }^{4}$}

${ }^{1}$ Museo de Historia Natural, Av. Arenales 1256, Aptdo. 14-0434, Lima 14, Perú.

susy 827@yahoo.com

${ }^{2}$ Herbario Vargas, Universidad Nacional San Antonio Abad, Cusco.

nosare@terra.com.pe

${ }^{3}$ Plant Resources Center, University of Texas at Austin, Austin TX 78712 EE.UU.

blanca.leon@mail.utexas.edu ${ }^{4}$ Herbario, Universidad Nacional de Cajamarca, Aptdo. 55, Cajamarca, Perú. svisidoro@yahoo.com

\section{Resumen}

La familia Gentianaceae es reconocida en el Perú por presentar alrededor de 15 géneros y aproximadamente de 170 especies (Brako \& Zarucchi, 1993; Ulloa Ulloa et al., 2004; S. Castillo, com.pers.), mayormente hierbas y arbustos. En este trabajo se reconoce 103 especies endémicas en siete géneros. Los géneros con mayor número de especies endemicas son Gentianella y Macrocarpaea. Las especies endémicas ocupan principalmente las regiones de la Puna Húmeda y Seca, Páramo y Bosque Muy Húmedo Montano, entre los 1000 y 5100 m de altitud. Se aplicaron las categorías y criterios de la UICN a 99 especies. Treinta y tres especies endémicas se encuentran representadas dentro de un área protegida.

Palabras claves: Gentianaceae, Gentianella, Macrocarpaea, Perú, endemismo, plantas endémicas.

\section{Abstract}

The Gentianaceae are represented in Peru by 15 genera and nearly 170 species (Brako \& Zarucchi, 1993; Ulloa Ulloa et al., 2004; S. Castillo, pers. comm.), mainly herbs and shrubs. Here we recognize 103 endemic species in seven genera. Gentianella and Macrocarpaea are the genera with the largest number of endemic species. Endemic Gentianaceae are found in the Humid and Dry Puna, Paramo and Very Humid Montane Forests regions, between 1000 and 5100 m elevation. We applied IUCN categories and criteria to 99 species. Thirty-three endemic species have been found to date in Peruvian protected areas.

Keywords: Gentianaceae, Gentianella, Macrocarpaea, Peru, endemism, endemic plants.

\section{Gentiana caspaltensis (Ball) J.S. Pringle

$$
\text { EN, Blab(iii) }
$$

Publicación: Phytologia 48(4): 281. 1981.

Colección tipo: J. Ball s.n.

Herbarios: GH, K.

Nombre común: Desconocido.

Registro departamental: JU, LI.

Regiones Ecológicas: PSH; 3800-4100 m.

SINAN PE: RNJ

Herbarios peruanos: USM (3).

Observaciones: Hierba anual, conocida de dos localidades en los pajonales de la parte central del país. La mayoría de los ejemplares de herbario conocidos provienen de la Reserva Nacional de Junín y alrededores. Las amenazas potenciales a la conservación de esta especie provienen del uso intensivo de los pajonales con fines agropastoriles, de extracción de vegetación de humedales y minería.

\section{Gentianella alborosea (Gilg) Fabris}

$$
\text { EN, Blab(iii) }
$$

Publicación: Bol. Soc. Arg. Bot. 6(1): 48. 1955.

Colección tipo: A. Weberbauer 6624

Henbarios: B, F, MO ; MOL!, USM!.

Nombre común: Harumpiri, hercampuri.

Registro departamental: JU.

Regiones Ecológicas: PSH; 4200-4500 m.

SINAN PE: Sin registro.

Herbarios penuanos: MOL (isotipo), USM (isotipo+2).

Observaciones: Especie herbácea, cespitosa conocida de unas pocas localidades, todas ellas en el centro del país. Forma parte de las praderas húmedas de la puna. Su uso como planta medicinal está ampliamente difundido, explotándose y extrayéndose poblaciones silvestres; junto con esa amenaza, otra preocupante es la proveniente de contaminación minera.

\section{Gentianella alborubra Fabris}

$$
\text { EN, Blab(iii) }
$$

Publicación: Bol. Soc. Arg. Bot. 6(1): 49-50, f. 1 J-L. 1955.

Colección tipo: F. Woytkowski 601

Herbarios: LP; MOL!, USM!.

Nombre común: Desconocido.

Registro departamental: CU.

Regiones Ecológicas: PSH; 3300-4000 m.

SINANPE: Sin registro.

Herbarios peruanos: CUZ (1), MOL (isotipo), USM (isotipo).

Observaciones: Esta hierba se conoce solamente de dos localidades ubicadas en los límites occidentales del Parque Nacional Manu. No ha vuelto a ser recolectada desde 1953. Probablemente incendios intencionales podrían afectar a esta especie.

\section{Gentianella andreae-mathewsii (Briq.) Zarucchi DD}

Publicación: Monogr. Syst. Bot. Missouri Bot. Gard. 45: 1255. 1993.

Colección tipo: A. Mathews

Herbarios:

Nombre común: Desconocido.

Registro departamental: AM.

Regiones Ecológicas: Sin datos; altitud desconocida.

SINANPE: Sin registro.

Herbarios peruanos: Ninguno.

Observaciones: Esta especie aparentemente es conocida solamente de la colección tipo, una planta recolectada en el siglo XIX.

Nota del Editor: En la versión on line de este artículo han sido omitidos los mapas del Perú que ilustraban el Registro departamental. Para ubicar las abreviaturas de los departamentos vea al final del artículo. 


\section{Gentianella brandtiana Gilg}

$$
\text { CR, Blab(iii) }
$$

Publicación: Bol. Soc. Argent. Bot. 6(1): 49. 1955.

Colección tipo: A. Weberbauer 5455

Herbarios: B.

Nombre común: D esconocido.

Registro departamental: AY.

Regiones Ecológicas: PSH; 4300-4400

m.

SINAN PE: Sin registro.

Herbarios peruanos: Ninguno.

Observaciones: Planta perenne, arrosetada conocida solamente de la localidad original, recolectada en 1910. Esta localidad se encontraba en las inmediaciones de una mina. Esta parte del suroccidente del país, entre Huancavelica y Ayacucho, ha sido escasamente herborizada.

\section{Gentianella brunneotincta (Gilg) J.S. Pringle

$$
\text { EN, Blab(iii) }
$$

Publicación: Monogr. Syst. Bot. Missouri Bot. Gard. 45: 1255. 1993.

Colección tipo: A. Weberbauer 3092

Henbarios: B, F; MOL!, USM!.

Nombre común: D esconocido.

Registro departamental: AN, LL, SM.

Regiones Ecológicas: PSH, PAR; 3900$4150 \mathrm{~m}$.

SINANPE: PNH, PNRA

Herbarios peruanos: HUT (1), MOL (isotipo), USM (isotipo+2).

Observaciones: Hierba conocida del norte del Perú, cuyas poblaciones fragmentadas están presentes en un área de $300 \mathrm{~km}^{2}$. Habita humedales altoandinos, por lo que las actividades mineras pueden afectar sus poblaciones.

\section{Gentianella calcarea (Gilg) J.S. Pringle CR, Blab(iii)}

Publicación: Monogr. Syst. Bot. Missouri Bot. Gard. 45: 1255. 1993.

Colección tipo: A. Weberbauer 2539

Herbarios: B, F; USM!.

Nombre común: D esconocido.

Registro departamental: JU.

Regiones Ecológicas: PSH; $4000 \mathrm{~m}$.

SINANPE: Sin registro.

Hemarios penuanos: USM (isotipo).

Observaciones: Esta especie herbácea es conocida aparentemente sólo del ejemplar tipo, una planta recolectada en 1903 en suelos calcáreos, probablemente de los alrededores de La O roya.

\section{Gentianella campanuliformis (Reimers) Fabris}

\section{EN, Bla}

Publicación: Bol. Soc. Arg. Bot. 7(2): 87. 1958. Colección tipo: F. Herrera 680

Herbarios: B, NY.

Nombre común: P'allcha.

Registro departamental: CU.

Regiones Ecológicas: MA, PSH; 2800-

$3900 \mathrm{~m}$

SINANPE: PNM

Herbarios penuanos: CUZ (2).
Observaciones: Planta perenne y arrosetada conocida de por lo menos tres localidades dispersas en el sur del Departamento de Cusco. Aparentemente esta especie ha sido recolectada hasta la década de 1960 en la misma localidad original.

\section{Gentianella carneorubra (Gilg) Fabris ex J.S. Pringle} VU, Bla

Publicación: Phytologia 48(4): 281. 1981. Colección tipo: A. Weberbauer 278

Herbarios: B.

Nombre común: D esconocido.

Registro departamental: HV, JU, LL, PA. Regiones Ecológicas: PSH; 3900-4674 $\mathrm{m}$.

SINAN PE: Sin registro.

Hemarios penuanos: HUT (1)?, USM (2).

Observaciones: Esta es una especie recolectada raras veces; crece aparentemente en grupos, pero no ocupa áreas grandes. Se conoce del sur de La Libertad a Huancavelica. En el centro del país, las subpoblaciones podrían estar afectadas por la extracción de material húmico de los humedales andinos.

\section{Gentianella centamalensis (Gilg) Zarucchi}

$$
\text { VU, Bla }
$$

Publicación: Monogr. Syst. Bot. Missouri Bot. Gard. 45: 1255. 1993.

Colección tipo: A. Stübel 41

Hemarios: B.

Nombre común: D esconocido. Registro departamental: AM, LL, PU. Regiones Ecológicas: PSH, PAR; 3500$4000 \mathrm{~m}$.

SINANPE: Sin registro.

Hemarios penuanos: HUT (3), USM (1).

Observaciones: Hierba perenne, conocida de varias localidades aisladas, en pajonales del norte y sur del país. La colección más antigua es la de Raimondi, realizada en 1864, en Q uichos, provincia de Carabaya, en el sur del país. El ejemplar tipo, sin embargo, procede de una localidad desconocida en Amazonas.

\section{Gentianella cenateae Fabris}

$$
\text { EN, Bla }
$$

Publicación: Bol. Soc. Argent. Bot. 6(1): 48-49, f. 1 G-I. 1955.

Colección tipo: E. Cerrate 1454

Herbarios: LP; USM!.

Nombre común: D esconocido.

Registro departamental: AN, LL.

Regiones Ecológicas: PSH, PAR; 3600$4160 \mathrm{~m}$.

SINANPE: Sin registro.

Herbarios peruanos: HUT (2), USM (isotipo).

Observaciones: Planta cespitosa, conocida de pocas localidades en el norte del país, del sur de La Libertad al sur de Ancash. Aparentemente, no ha sido recolectada desde 1961, dado que las áreas de donde se conoce han sido poco herborizadas. 


\section{Gentianella chamuchui (Reimers) Fabris}

\section{NT}

Publicación: Bol. Soc. Arg. Bot. 7(2): 91. 1958.

Colección tipo: A. Weberbauer 7010

Henbarios: B; MOL!, USM!

Nombre común: Chamuchui, lorambo, shalcadino.

Registro departamental: AN, CA, LL. Regiones Ecológicas: PAR; 3300-4700 $\mathrm{m}$.

SINAN PE: Sin registro.

Herbarios peruanos: CPUN (1), HAO (1), HUT (2), MOL (isotipo), USM (isotipo+4).

Observaciones: Esta hierba perenne se conoce del sur de Cajamarca al norte de Ancash, donde es típica de ambientes paramunos. Poblaciones de esta especie se hallan en los límites del Parque Nacional del Río Abiseo. Una de las poblaciones a altitudes más elevadas, se encuentra en la Cordillera de Pelagatos, una zona con varios endemismos que requiere de atención de botánicos y conservacionistas.

\section{Gentianella chlorantha J.S. Pringle \\ CR, Blab(iii)}

Publicación: Sida 11(4): 357-360, f. 12. 1986.

Colección tipo: P.J. Barbour 3439

Herbarios: HAM, MO.

Nombre común: D esconocido.

Registro departamental: AM.

Regiones Ecológicas: PAR; 3200-3300 m.

SINAN PE: ZRCC

Herbarios peruanos: Ninguno.

Observaciones: Hierba terrestre conocida solamente de una localidad. No ha vuelto a ser recolectada desde 1978. Probablemente se encuentre entre otras áreas paramunas, pero a pesar de las herborizaciones recientes no hay material adicional. La localidad original se encuentra en proceso de evaluación para definir su estatus de conservación (Zona Reservada), siendo las amenazas más importantes el deterioro del hábitat por pastoreo y agricultura.

\section{Gentianella coccinea (D. Don ex G. Don) Zarucchi}

DD

Publicación: Monogr. Syst. Bot. Missouri Bot. Gard. 45: 1255. 1993.

Colección tipo: J. Pavón s.n.

Herbarios: B?.

Nombre común: D esconocido.

Registro departamental: $\mathrm{HU}$.

Regiones Ecológicas: MA; altitud desconocida.

SINAN PE: Sin registro.

Herbarios peruanos: Ninguno.

Observaciones: Esta especie herbácea fue descrita de una planta recolectada en el siglo XVIII, de la cual se desconoce su procedencia. Se conoce también de laderas rocosas en el centro del país. Aparentemente no ha vuelto a ser recolectada desde 1922.

\section{Gentianella corallina (Gilg) Zarucchi}

\section{EN, Blab(iii)}

Publicación: Monogr. Syst. Bot. Missouri Bot. Gard. 45: 1255. 1993.

Colección tipo: A. Weberbauer 4294

Herbarios: $B$.

Nombre común: D esconocido.

Registro departamental: AM, PA.

Regiones Ecológicas: PAR; 3250-3750

m.

SINAN PE: Sin registro.

Herbarios peruanos: USM (2).

Observaciones: Especie herbácea conocida de tres localidades en la cuenca del Utcubamba y una en la del Huertas, un tributario del Huallaga. La población mejor representada proviene de los Cerros Calla Calla, la cual debería ser de interés para la conservación por los endemismos que alberga.

\section{Gentianella crassicaulis J.S. Pringle}

$$
\text { VU, B lab(iii) }
$$

Publicación: Monogr. Syst. Bot. Missouri Bot. Gard. 45: 1255. 1993.

Colección tipo: W. Lobb s.n.

Herbarios: $B$.

Nombre común: D esconocido.

Registro departamental: CA, CU, LL. Regiones Ecológicas: PSH, PAR; 3000$4078 \mathrm{~m}$.

SINAN PE: Sin registro.

Herbarios penuanos: CPUN (3), HAO (2), HUT (1)?.

Observaciones: Hierba conocida de varias localidades aisladas en el norte y sur del país, donde es localmente escasa. Casi todas las colecciones en Cajamarca proviene del Paso de Kumulka, ruta a Celendín, mientras que en La Libertad es abundante en el Nevado Huaylillas. Amenazas a sus poblaciones están asociados a deterioro del hábitat por pastoreo intensivo.

\section{Gentianella crossolaema (Wedd.) Zarucchi CR, B 1ab(iii)}

Publicación: Monogr. Syst. Bot. Missouri Bot. Gard. 45: 1255. 1993.

Colección tipo: H.A. Weddell s.n.

Herbarios:

Nombre común: D esconocido.

Registro departamental: CU.

Regiones Ecológicas: PSH; altitud desconocida.

SINAN PE: Sin registro.

Herbarios peruanos: Ninguno.

Observaciones: Hierba conocida solamente de la descripción original, de una planta recolectada en el siglo XIX. La localidad precisa se desconoce, pero se sabe que esta especie fue encontrada entre la cuenca del Urubamba y la del Yanatilli, probablemente cerca al Abra Málaga. Aparentemente no existen recolectas adicionales. 


\section{Gentianella dianthoides (Kunth) Fabris ex J.S. Pringle}

$$
\text { VU, Blab(iii) }
$$

Publicación: Sida 11(4): 368. 1986.

Colección tipo: A. Humboldt \& A. Bonpland

Henbarios: P.

Nombre común: D esconocido.

Registro departamental: AN, AY, CA, HU. Regiones Ecológicas: PSH, PAR; 3300$4050 \mathrm{~m}$.

SINANPE: Sin registro.

Hemarios penuanos: CPUN (5), HAO (2), HUT(1)?, USM (8).

Observaciones: Esta especie se conoce de varias colecciones procedentes de Cajamarca, realizadas en la jalca, así como en la vegetación de puna en el sur del país. El área de presencia de esta especie alcanza los $10.000 \mathrm{~km}^{2}$. Amenazas a sus poblaciones provienen del pastoreo y la quema de los pajonales altoandinos.

\section{Gentianella dilatata (Griseb.) Fabris}

EN, Blab(iii)

Publicación: Bol. Soc. Argent. Bot. 7(2): 90. 1958.

Colección tipo: A. Mathews 1152

Hemanios: MO.

Nombre común: D esconocido.

Registro departamental: HV, JU, LL.

Regiones Ecológicas: PSH; 4000-4500

m.

SINANPE: Sin registro.

Herbarios peruanos: MOL (1), USM (3).

Observaciones: Hierba conocida de por lo menos cinco localidades en el centro del país. Macbride (1959) comentó que el ejemplar tipo, recolectado en el siglo XIX, podría provenir de Junín, en donde ha sido recolectado en otras oportunidades. Amenazas a sus poblaciones podrían estar asociadas a actividades mineras y pastoreo intensivo. Parece atribuirsele propiedades medicinales, pero se desconoce si se explotan sus poblaciones para el comercio.Por estar asociada a humedales, cambios climáticos severos podrían afectarla.

\section{Gentianella dissitifolia (Griseb.) Zarucchi}

Publicación: Monogr. Syst. Bot. Missouri Bot. Gard. 45: 1255. 1993.

Colección tipo: J. D ombey 394

Herbarios: MO.

Nombre común: D esconocido.

Registro departamental: JU.

Regiones Ecológicas: MA; altitud desconocida.

SINAN PE: Sin registro.

Herbarios peruanos: Ninguno.

Observaciones: Hierba perenne, conocida al parecer sólo de la localidad original en la cuenca del Palca. Este taxón fue considerado por Brako \& Zarucchi (1993) como un endemismo; sin embargo, no ha sido posible evaluarlo, ni asignarle una categoría.

\section{Gentianella dombeyana (Wedd.) Zarucchi}

DD

Publicación: Monogr. Syst. Bot. Missouri Bot. Gard. 45: 1255. 1993.

Colección tipo: J. D ombey s.n.

Hembarios: MO, P.

Nombre común: D esconocido.

Registro departamental: JU.

Regiones Ecológicas: Sin datos; altitud desconocida.

SINAN PE: Sin registro.

Herbarios peruanos: USM (1).

Observaciones: Esta especie subarbustiva qse conoce solamente decolecciones realizadas en los siglosXVIII yXIX. Ninguna colección incluye información detallada de localidades y de las poblaciones.

\section{Gentianella ericothamna (Gilg) Zarucchi}

\section{CR, B1a}

Publicación: Monogr. Syst. Bot. Missouri Bot. Gard. 45: 1255. 1993.

Colección tipo: A. Weberbauer 3381

Herbarios: B, MO.

Nombre común: Desconocido.

Registro departamental: HU.

Regiones Ecológicas: PSH; 3400 m.

SINAN PE: Sin registro.

Herbarios peruanos: Ninguno.

Observaciones: Esta hierba es conocida sólo de la descripción original, de una planta recolectada en 1903 en la cuenca alta del Monzón. Esta cuenca alberga otros endemismos, pero no ha sido herborizada en detalle desde entonces. Al igual que muchas especies en el género, esta habita humedales. Amenazas a sus poblaciones podrían estar asociadas a las actividades agropastoriles.

\section{Gentianella ernestii (Briquet) Fabris ex J.S. Pringle}

$$
\text { EN, B1a }
$$

Publicación: Phytologia 48(4):281. 1981. Colección tipo: A. Weberbauer 4870

Herbarios: $F$.

Nombre común: D esconocido.

Registro departamental: CU.

Regiones Ecológicas: PSH; 3200-3900 m.

SINANPE: PNM

Herbarios penuanos: USM (14).

Observaciones: Esta hierba es conocida de varias localidades en el Departamento de Cusco. La colección original fue recolectada en 1905, delosalrededores deCusco; sin embargo, la mayoníadelosejemplares, proceden de poblaciones en el Parque Nacional Manu. Aparentemente, podńa estar representada en Bolivia, pero no se verificó la identificación de ese ejemplar boliviano en el herbario de Missouri.

\section{Gentianella euphorbiifolia Fabris}

\section{CR, Bla}

Publicación: Bol. Soc. Argent. Bot. 6(1): 50, f. 1 M-P. 1955.

Colección tipo: R. Ferreyra 1316

Hemarios: LP; USM!.

Nombre común: Desconocido.

Registro departamental: LL.

Regiones Ecológicas: PAR; altitud desconocida.

SINAN PE: Sin registro.

Herbarios peruanos: USM (isotipo). 
Observaciones: Este subarbusto se conoce solamente de una localidad, en las partes altas con vegetación de jalca, en La Libertad. Estalocalidad ha sido escasamente herborizada. Amenazas podrían estar asociadas a modificación del hábitat. Aparentemente, no ha vuelto a ser recolectada desde 1946.

\section{Gentianella eurysepala (Gilg) Zarucchi}

$$
\text { EN, B lab(iii) }
$$

Publicación: Monogr. Syst. Bot. Missouri Bot. Gard. 45: 1255. 1993.

Colección tipo: A. Weberbauer 5676

Herbarios: B, F, MO, US.

Nombre común: D esconocido.

Registro departamental: HV.

Regiones Ecológicas: PSH; 3400-3800 m.

SINAN PE: Sin registro.

Herbarios penuanos: USM (2).

Observaciones: Esta especie herbácea se conoce solamente de la cuenca del río Mantaro. La colección tipo fue recolectada en 1910 de pajonales. Las recolectas más recientes provienen aparentemente de 1954, en parte debido al escaso interés en herborizar en zonas andinas. Amenazas a sus poblaciones podrían estar asociadas al pastoreo y actividades mineras.

\section{Gentianella fruticulosa (Dombey ex Wedd.) Fabris ex J.S. Pringle

$$
\text { EN, Blab(iii) }
$$

Publicación: Monogr. Syst. Bot. Missouri Bot. Gard. 45: 1255. 1993.

Colección tipo: J. D ombey s.n.

Herbarios: $P$.

Nombre común: D esconocido.

Registro departamental: AN, AY, JU, PA. Regiones Ecológicas: BPM, PSH; 3300$4400 \mathrm{~m}$.

SINAN PE: PNYC

Herbarios peruanos: USM (3).

Observaciones: Planta perenne conocida de pajonales en humedales de por lo menos cinco localidades en el centro del país. Esta especie ha sido recolectada desde el sur del D epartamento de Ancash, en la cuenca alta del Pativilca hasta el nor-oriente de Ayacucho, en la cuenca del A purímac. Una población está protegida oficialmente. Fuera de esa área amenazas a sus poblaciones podrían estar asociadas a incendios intencionales con fines de deforestación.

\section{Gentianella gilgiana (Reimers) Fabris ex J.S. Pringle

$$
\text { EN, Blab(iii) }
$$

Publicación: Sida 11(4): 368. 1986. Colección tipo: A. Weberbauer 7011 Herbarios: B, US; MOL!, USM!.

Nombre común: Yangamarsha. Registro departamental: LL. Regiones Ecológicas: PAR, AA; 4400$4700 \mathrm{~m}$.

SINAN PE: Sin registro.

Herbarios peruanos: HUT (1), MOL (isotipo), USM (isotipo).

Observaciones: Hierba conocida de tres localidades en el norte del país. El área de presencia no supera los $5000 \mathrm{~km}^{2}$.Todos los registros conocidos provienen de los alrededores del Nevado Huaylillas, una zona que alberga varios endemismos; pero esas localidades están sujetas a la minería y pastoreo intensivo.

\section{Gentianella herrerae (Reimers) Zarucchi}

$$
\text { CR, Bla }
$$

Publicación: Monogr. Syst. Bot. Missouri Bot. Gard. 45: 1255. 1993.

Colección tipo: F. Herrera 287

Hemarios: $\mathrm{B}$.

Nombre común: Pfallchahuiconloi.

Registro departamental: CU.

Regiones Ecológicas: PSH; 3900-4200 m.

SINANPE: Sin registro.

Herbarios peruanos: Ninguno.

Observaciones: Hierba conocida aparentemente sólo de la colección tipo, una planta recolectada en 1926, al sur del D epartamento de Cusco, en la cuenca alta del Paucartambo. Esta parte de la cuenca ha sufrido cambios marcados en sus ambientes naturales.

\section{Gentianella huancaveliquensis Fabris}

\section{EN, Blab(iii)}

Publicación: Bol. Soc. Argent. Bot. 6(1): 46-48, f. 1 D-F. 1955.

Colección tipo: 0 . Tovar 734

Hemarios: LP; USM!

Nombre común: D esconocido.

Registro departamental: HV.

Regiones Ecológicas: PSH; 4000 m.

SINAN PE: Sin registro.

Herbarios peruanos: USM (isotipo).

Observaciones: Hierba perenne, diminuta, conocida de las cuencas del Pampas y del Apurímac. Aparentmente no ha vuelto a ser recolectada desde 1953. Esta parte del país y en especial esas cuencas no han vuelto a ser herborizadas en detalle desde entonces.

\section{Gentianella incurva (H ook.) Fabris}

$$
\text { EN, Blab(iii) }
$$

Publicación: Bol. Soc. Argent. Bot. 7(2): 90. 1958

Colección tipo: A. Cruckshanks s.n.

Herbarios: $\mathrm{K}$.

Nombre común: Rimac-rimac.

Registro departamental: HU, JU, PA.

Regiones Ecológicas: PSH; 3600-4200 m.

SINAN PE: SNH

Herbarios peruanos: USM (3).

Observaciones: Hierba conocida de pajonales altoandinos en el centro del país. Esta especie fue descrita de una planta recolectada en el siglo XIX en Huallay, hoy un Santuario Nacional, aunque aparentemente no ha vuelto a ser recolectada ahi. No se conoce de colecciones recientes, probablemente por la poca herborización en la zona altoandina.

\section{Gentianella lilacina (Gilg) Zarucchi}

$$
\text { CR, Blab(iii) }
$$

Publicación: Monogr. Syst. Bot. Missouri Bot. Gard. 45: 1255. 1993.

Colección tipo: A. Weberbauer 3223

Herbarios: B; MOL!, USM!.

Nombre común: Sajhuacache.

Registro departamental: AN.

Regiones Ecológicas: MA; 3200 m.

SINANPE: Sin registro.

Henbarios peruanos: MOL (isotipo), USM (isotipo). 
Observaciones: Esta hierba terrestre es conocida sólo de una localidad en la Cordillera Negra. El ejemplar tipo fue recolectado en 1903 y aparentemente no ha vuelto a ser recolectado en esa cordillera o en el Parque Nacional Huascarán. Esta especie crecía en matorrales ralos. Amenazas asociadas a esos ambientes están vinculadas a los incendios intencionales.

\section{Gentianella liniflora (Kunth) Fabris ex J. Pringle}

$$
\text { VU, Bla }
$$

Publicación: Monogr. Syst. Bot. Missouri Bot. Gard. 45: 1255. 1993.

Colección tipo: A. Humboldt \& A. Bonpland s.n.

Herbarios: B.

Nombre común: Shagapa morada. Registro departamental: AM, PI. Regiones Ecológicas: MDE, MA, PAR, BMHM; 1900- 3000 m.

SINANPE: Sin registro.

Herbarios penuanos: CPUN (2), HAO (2).

Observaciones: Hierba considerada por Macbride (1959) como una bianual. Esta especie es conocida de varias localidades en el norte del país, donde crece en ambientes con vegetación secundaria. Esta especie es conocida de las cuencas de Huancabamba y del Marañón.

\section{Gentianella lobelioides (Gilg) Zarucchi CR, Blab(iii)}

Publicación: Monogr. Syst. Bot. Missouri Bot. Gard. 45: 1255. 1993.

Colección tipo: A. Weberbauer 955

Hembarios: B.

Nombre común: D esconocido.

Registro departamental: PU.

Regiones Ecológicas: AA; 4600-4700 m.

SINAN PE: Sin registro.

Herbarios peruanos: Ninguno.

Observaciones: Esta hierba altoandina es conocida aparentemente sólo dela descripción original. El ejemplar tipo crecía formando un césped bajo y fue recolectado en 1902, en la cuenca del Suche. Podría estar representada en la flora boliviana.

\section{Gentianella luridoviolacea (Gilg) J.S. Pringle}

$$
\text { EN, Blab(iii) }
$$

Publicación: Monogr. Syst. Bot. Missouri Bot. Gard. 45: 1255. 1993.

Colección tipo: A. Weberbauer 3759

Herbarios: B.

Nombre común: Desconocido.

Registro departamental: JU, LI, PA.

Regiones Ecológicas: AA; 4200-4500

$\mathrm{m}$.

SINANPE: Sin registro.

Hemarios peruanos: Ninguno.

Observaciones: Esta hierba arrosetada es conocida de la parte altoandina del centro del país, de por lo menos cuatro localidades aisladas. Aparentemente está asociada a rocas calcáreas. Poco se sabe de su historia natural y este es un caso de interés por aclarar. Probablemente actividades mineras podrían afectar sus poblaciones.
35. Gentianella luteomarginata (Reimers) Fabris

$$
\text { EN, Bla }
$$

Publicación: Bol. Soc. Argent. Bot. 6(1): 46, ad nota. 1955.

Colección tipo: F. Herrera 1036

Herbarios: B.

Nombre común: Azul ppallcha.

Registro departamental: CU.

Regiones Ecológicas: PSH; 3500-4300 m.

SINANPE: SHMP

Herbarios peruanos: Ninguno.

O bservaciones: Esta hierba es conocida de localidades aisladas en el sur del país, en las cuencas del Apurímac, Yavero y Urubamba. Solamente una población está en un área protegida. Su tamaño es pequeño que la haría pasar desapercibida, aunque posee flores atractivas que desarrollan en diferentes épocas del año.

\section{Gentianella muscoides (Gilg) J.S. Pringle$$
\text { CR, B lab(iii) }
$$

Publicación: Monogr. Syst. Bot. Missouri Bot. Gard. 45: 1255. 1993.

Colección tipo: A. Weberbauer 96

Herbarios: B.

Nombre común: D esconocido.

Registro departamental: JU.

Regiones Ecológicas: AA; 4600 m.

SINAN PE: Sin registro.

Herbarios peruanos: Ninguno.

Observaciones: Esta especie es conocida solamente de la descripción original, de una planta recolectada a inicios del siglo $\mathrm{XX}$, al pie de un glaciar de la Cordillera Central en el suroeste de Lima; glaciar que desafortunadamente ha desaparecido debido a cambio climático (Pettersen, 1967).

\section{Gentianella nitida (Grisebach) Fabris

$$
\text { EN, B1a }
$$

Publicación: Bol. Soc. Argent. Bot. 7(2): 91. 1958.

Colección tipo: A. Cruckshanks s.n.

Herbarios: B.

Nombre común: Mincha.

Registro departamental: $\mathrm{HU}, \mathrm{HV}$, JU, LL.

Regiones Ecológicas: PSH; $4100 \mathrm{~m}$.

SINAN PE: RNJ

Herbarios penuanos: MOL (1), USM (3).

Observaciones: Hierba cespitosa, formando rosetas, conocida de varias localidades con humedales, en el centro del país, desde la cuenca alta del Santa Cruz en Huánuco a la cuenca del Apurímac en Huancavelica. Estos ambientes están afectados por la expansión de la actividad minera y pastoreo intensivo. Sus poblaciones también están siendo explotadas, por considerársele medicinal. 


\section{Gentianella oreosilene (Gilg) J.S. Pringle}

$$
\text { EN, B1ab(iii) }
$$

Publicación: Monogr. Syst. Bot. Missouri Bot. Gard. 45: 1255. 1993.

Colección tipo: A. Weberbauer 4288

Henbarios: B; USM!.

Nombre común: D esconocido.

Registro departamental: AM, AN, HU.

Regiones Ecológicas: PAR, BPM; 3100-3400 m.

SINAN PE: Sin registro.

Herbarios penuanos: USM (isotipo+6).

Observaciones: Especie herbácea conocida de la jalca en la vertiente oriental andina del norte y centro del país, donde ha sido hallada en, por lo menos, cinco localidades naturalmente aisladas. El ejemplar tipo fue recolectado en 1904, de la cuenca alta del Utcubamba. La población mejor representada en colecciones de herbario proviene de los Cerros Calla Calla, una zona montañosa que alberga varios otros endemismos.

\section{Gentianella pavonii (Grisebach) Fabnis}

$$
\text { EN, B lab(iii) }
$$

Publicación: Bol. Soc. Argent. Bot. 7(2): 89. 1958

Colección tipo: H. Ruiz s.n.

Herbarios: G.

Nombre común: D esconocido

Registro departamental: AP, AY, HV, JU. Regiones Ecológicas: PSH, AA; 3300$4500 \mathrm{~m}$.

SINAN PE: Sin registro.

Herbarios peruanos: USM (3).

Observaciones: Hierba palustre, conocida del centro y sur del país. Estaespeciese conoce delas vecindades de humedales andinos queestán sujetos a pastoreo, incendios intencionales y otras veces a la minería. Estas actividades podrían amenazar a las poblaciones conocidas.

\section{Gentianella pernettyoides (Reimers) Fabris}

$$
\text { EN, Bla }
$$

Publicación: Bol. Soc. Argent. Bot. 7(2): 91. 1958

Colección tipo: A. Weberbauer 7026

Henbarios: G H; MOL!, USM!

Nombre común: D esconocido.

Registro departamental: LL, SM.

Regiones Ecológicas: PAR; 3600-4000 m.

SINAN PE: PNRA

Herbarios peruanos: HUT (1),MO L

(isotipo), USM (isotipo+8)

Observaciones: Hierba conocida del nor-oriente del país, de subcuencas altas del Marañón, así como de las cuencas del Abiseo y Montecristo, ambos afluentes del Huallaga. Esta especie ocupa humedales con numerosos individuos.

\section{Gentianella persquarrosa (Reimers) J.S. Pringle EN, Blab(iii)}

Publicación: Sida 11(4): 368. 1986.

Colección tipo: F. Herrera 1020

Herbarios: B.

Nombre común: Ckello pfallcha.

Registro departamental: CU.

Regiones Ecológicas: PSH; 3700 m.

SINANPE: Sin registro.

Herbarios penuanos: CUZ (10).
Observaciones: Esta especie herbácea es conocida solamente del sur del país, de las cuencas altas del Paucartambo, Urubamba y Apurímac. Aparentemente no ha vuelto a ser recolectada desde la década de 1960.

\section{Gentianella petrophila (Gilg) Zarucchi}

$$
\text { EN, Blab(iii) }
$$

Publicación: Monogr. Syst. Bot. Missouri Bot. Gard. 45:1256. 1993

Colección tipo: A. Weberbauer 2562

Henbarios: B; USM!

Nombre común: D esconocido.

Registro departamental: HU, JU.

Regiones Ecológicas: PSH; 3700-3800

m.

SINAN PE: Sin registro.

Herbarios peruanos: USM (isotipo).

Observaciones: Esta hierba perenne es conocida de tres localidades aisladas en la parte altoandina del centro del país. El ejemplar tipo fue recolectado en 1903, de laderas rocosas en una subcuenca del Mantaro. Otras poblaciones han sido registradas de la cuenca del Huertas, un afluente del Huallaga y de la porción media del Mantaro. Aparentemente no ha vuelto a ser recolectada desde la década de 1920. Actividades mineras podrían ser un tema de preocupación para esta especie. Se requiere de nuevas herborizaciones en las partes altas de las cuencas mencionadas.

\section{Gentianella poculifera (Gilg) Zarucchi CR, Bla}

Publicación: Monogr. Syst. Bot. Missouri Bot. Gard. 45: 1256. 1993.

Colección tipo: A. Weberbauer s.n.

Herbarios: $\mathrm{B}$.

Nombre común: D esconocido.

Registro departamental: JU.

Regiones Ecológicas: PSH; 3500-3600 m.

SINAN PE: Sin registro.

Herbarios peruanos: Ninguno.

Observaciones: Esta hierba perenne es conocida aparentemente de una sola localidad en el centro el país. El ejemplar tipo fue recolectado a inicios del siglo XX en la cuenca del Palca, un tributario del Perené.

\section{Gentianella porphyrantha (Gilg) Zarucchi}

$$
\text { CR, Bla }
$$

Publicación: Monogr. Syst. Bot. Missouri Bot. Gard. 45: 1256. 1993.

Colección tipo: A. Weberbauer 2803

Hemanios: $B$.

Nombre común: D esconocido.

Registro departamental: AN.

Regiones Ecológicas: AA; 4400-4600 m.

SINAN PE: Sin registro.

Herbarios peruanos: Ninguno.

Observaciones: Hierba perenne conocida aparentemente sólo de la localidad tipo, ubicada en la cuenca alta del Pativilca. Esta especie fue recolectada en 1903 en un área dela Cordillera Huayhuash, hoy una Zona Reservada. Probablemente ocupaba laderas rocosas. 


\section{Gentianella potamophila (Gilg) Zanucchi}

$$
\text { EN, Bla }
$$

Publicación: Monogr. Syst. Bot. Missouri Bot. Gard. 45: 1256. 1993.

Colección tipo: A. Weberbauer 6907

Herbarios: B; MOL!, USM!.

Nombre común: D esconocido.

Registro departamental: AP, AR, AY, CU.

Regiones Ecológicas: PSH; 3900-4100

m.

SINANPE: RNPG

Herbarios peruanos: MOL (isotipo), USM (isotipo+1).

Observaciones: Hierba perenne, conocida aparentemente de cuatro localidades en el sur del país. Las poblaciones ocupan humedales andinos en las cuencas del Apurímac, Grande y Urubamba. Solamente una población se halla en un área protegida. La colección más reciente proviene de 1970.

\section{Gentianella pseudolycopodium (Gilg) J. Pringle CR, Blab(iii)}

Publicación: Monogr. Syst. Bot. Missouri Bot. Gard. 45: 1256. 1993.

Colección tipo: A. Weberbauer 3353

Herbarios: B; USM!.

Nombre común: D esconocido.

Registro departamental: HU.

Regiones Ecológicas: MA; 3400-3500

$\mathrm{m}$

SINANPE: Sin registro.

Herbarios penuanos: USM (isotipo).

Observaciones: Hierba conocida solamente de la colección tipo, una planta recolectada en 1903, en la cuenca del Monzón, la cual ha recibido escaso estudio florístico desde entonces. Habita matorrales abiertos en zonas pantanosas,por lo que amenazas a sus poblaciones estarían asociadas a pastoreo intensivo.

\section{Gentianella raimondiana (Wedd.) J. Pringle}

$$
\text { EN, Blab(iii) }
$$

Publicación: Monogr. Syst. Bot. Missouri Bot. Gard. 45: 1256. 1993.

Colección tipo: A. Raimondi s.n.

Herbarios: B.

Nombre común: D esconocido.

Registro departamental: CA.

Regiones Ecológicas: PAR; $3800 \mathrm{~m}$.

SINANPE: Sin registro.

Hemarios penuanos: HUT (1), USM (1).

Observaciones: Esta especie herbácea es conocida aparentemente sólo del norte del país. En el herbario San Marcos (USM) existe un ejemplar de Raimondi recolectado en Hualgayoc, D epartamento de Cajamarca, que podría corresponder al material tipo. O tros ejemplares provienen de las cuencas altas del Chusgón y el Crisnejas, ambos afluentes del Marañón. Como en el caso de otras especies paramunas, los incendios intencionales y la actividad minera podrían considerarse de preocupación.

\section{Gentianella rima (D. Don ex G. Don) Fabris}

$$
\text { EN, Bla }
$$

Publicación: Bol. Soc. Argent. Bot. 7(2): 90. 1958.

Colección tipo: H. Ruiz \& J. Pavón s.n.

Herbarios: BM, MA, MO.

Nombre común: Phlallcha, Rima rima.

Registro departamental: CU, JU, PA.

Regiones Ecológicas: PSH; 3200-4280

$\mathrm{m}$.

SINAN PE: PNM

Herbarios penuanos: CUZ (1)?, USM (5).

Observaciones: Esta herbácea perenne es conocida de por lo menos cinco localidades del centro y sur del país. Esta especie fue descrita de una planta recolectada en el siglo XVIII. Poblaciones adicionales se hallan en las cuencas del Urubamba, Mantaro y Perené. Una población está en el Parque Nacional Manu.

\section{Gentianella roseolilacina (Gilg) J. Pringle}

\section{NE}

Publicación: Monogr. Syst. Bot. Missouri Bot. Gard. 45: 1256. 1993.

Colección tipo: A. Weberbauer 2952

Herbarios: B; MOL!, USM!.

Nombre común: D esconocido.

Registro departamental: AN.

Regiones Ecológicas: PSH; 3700-4400 $\mathrm{m}$.

SINANPE: PNH

Hemarios penuanos: MOL (isotipo), USM (isotipo+8).

Observaciones: Esta hierba es conocida de la Cordillera Blanca, de por lo menos seis localidades. El ejemplar tipo proviene de los alrededores de Laguna Querococha, en el sur del Parque Nacional Huascarán. Esta especieno se evalúa hasta aclarar un posible registro de presencia en Bolivia, que de confirmarse constituiría un caso de disyunción o de escasa recolección de la especie en el Perú.

\section{Gentianella sanctonum (Gilg) J. Pringle}

$$
\text { EN, B1a }
$$

Publicación: Phytologia 48(4): 284. 1981. Colección tipo: A. Weberbauer 2959

Herbarios: B; MOL!, USM!.

Nombre común: O kemakaschka, okimaka. Registro departamental: AN.

Regiones Ecológicas: PSH, AA; 4000$4400 \mathrm{~m}$.

SINANPE: PNH

Hembarios penuanos: MOL (isotipo), USM (isotipo+2).

Observaciones: Esta hierba es conocida, al igual que Getiandla rosedilaina, solamente de localidades en la Cordillera Blanca. El ejemplar tipo fue recolectado probablemente en los alrededores de la laguna Querococha, en el sur del Parque Nacional Huascarán. Sus inflorescencias son empleadas localmente como ornamento. 


\section{Gentianella saxicola (Grisebach) J. Pringle}

$$
\text { EN, Bla }
$$

Publicación: Monogr. Syst. Bot. Missouri Bot. Gard. 45: 1256. 1993.

Colección tipo: A. Mathews s.n.

Hemarios: $\mathrm{K}$.

Nombre común: D esconocido.

Registro departamental: JU, PA.

Regiones Ecológicas: PSH; altitud desconocida.

SINANPE: RNJ

Herbarios peruanos: Ninguno.

Observaciones: Esta hierba es conocida solamente del centro del país, de la Meseta de Bombón. A parentemente, fue recolectada en los alrededores de la laguna de Junín, hoy parte dela Reserva Nacional de Junín. Al parecer, no ha vuelto a ser recolectada ahí desde la década de 1940.

\section{Gentianella scarlatinostriata (Gilg) Zarucchi EN, Blab(iii)}

Publicación: Monogr. Syst. Bot. Missouri Bot. Gard. 45: 1256. 1993.

Colección tipo: A. Weberbauer 6621

Hembarios: B; MOL!, USM!.

Nombre común: Chunchuhuaita.

Registro departamental: HV, JU.

Regiones Ecológicas: AA; $4300 \mathrm{~m}$.

SINANPE: Sin registro.

Herbarios peruanos: MO L (isotipo), USM

(isotipo+1).

Observaciones: Hierba arrosetada, aparentemente distribuida en el centro del país. Fue descrita de un ejemplar recolectado en la cuenca alta del Tulumayo, en 1913. Poco se sabe del estado de las poblaciones de esta especie; sin embargo, fue reportada de un glaciar en retroceso, por lo que podría verse afectada por cambios climáticos. La colección más reciente que se conoce proviene de un ejemplar comprado en el mercado, empleado como ornamental para una fiesta patronal.

\section{Gentianella setipes (Gilg) J. Pringle}

$$
\text { EN, Blab(iii) }
$$

Publicación: Monogr. Syst. Bot. Missouri Bot. Gard. 45: 1256. 1993.

Colección tipo: A. Weberbauer 6322

Herbarios: B.

Nombre común: Campanilla.

Registro departamental: PI, LL.

Regiones Ecológicas: PAR; 3200 m.

SINAN PE: Sin registro.

Hembarios penuanos: HUT (1).

Observaciones: Hierba perenne, conocida solamente de dos localidades en el norte de la vertiente del Pacífico. Un ejemplar proveniente de Cusco es dudoso y se excluye. Al parecer, no ha vuelto a ser recolectada desde 1971. Incendios intencionales y pastoreo podrían ser temas de preocupación para su conservación.

\section{Gentianella speciosissima (Gilg) Zarucchi}

$$
\text { EN, Blab(iii) }
$$

Publicación: Monogr. Syst. Bot. Missouri Bot. Gard. 45: 1256. 1993.

Colección tipo: A. Stübel 24b, 25

Herbarios: $B$.

Nombre común: D esconocido.

Registro departamental: AM.

Regiones Ecológicas: PAR, BPM; 2800$3600 \mathrm{~m}$.

SINAN PE: Sin registro.

Herbarios peruanos: USM (4).

Observaciones: Hierba perenne, conocida de la cuenca alta del Utcubamba. Habita ambientes paramunos con arbustos dispersos que podrían estar afectados por incendios intencionales. Aparentemente no ha vuelto a ser recolectada desde 1964.

\section{Gentianella thyrsoidea (H ook.) Fabris \\ NT}

Publicación: Bol. Soc. Argent. Bot. 7(2): 88. 1958.

Colección tipo: A. Cruckshanks s.n.

Herbarios: K.

Nombre común: Japalan shacoj

Registro departamental: AN, AY, HU, JU, LL, PA.

Regiones Ecológicas: PSH, PAR, AA; 3800-4900 m.

SINANPE: PNRA, PNH, SNH

Herbarios peruanos: CPUN (2), HUT (1), USM (17).

Observaciones: Hierba perenne conocida de varias localidades en el norte y centro del país, en las cuencas del Mantaro, Marañón y Santa. El ejemplar tipo fue recolectado en el siglo XIX en una localidad hoy parte del Santuario Nacional Huaillay.

\section{Gentianella tovariana Fabris}

\section{CR, Bla}

Publicación: Bol. Soc. Argent. Bot. 6(1): 45-46, f. 1 A-C. 1955.

Colección tipo: 0 . Tovar 874

Herbarios: LP; USM!

Nombre común: D esconocido.

Registro departamental: HV.

Regiones Ecológicas: PSH; 4000 m.

SINAN PE: Sin registro.

Herbarios peruanos: USM (isotipo+1).

Observaciones: Hierba perenne, arrosetada, que se conoce solamente de una localidad en Huancavelica, en la cuenca del Mantaro. La localidad y ambiente de donde se conoce esta especie ha sido poco herborizada. Además, el D epartamento se considera, en general, dentro de un área con vacío de información botánica. 


\section{Gentianella tristicha (Gilg) J. Pringle}

$$
\text { VU, B 1ab(iii) }
$$

Publicación: Monogr. Syst. Bot. Missouri Bot. Gard. 45: 1256. 1993.

Colección tipo: A. Weberbauer 2933

Herbarios: B; MOL!, USM!.

Nombre común: D esconocido.

Registro departamental: AM, AN, LL.

Regiones Ecológicas: $\mathrm{PSH}, \mathrm{PAR}, \mathrm{AA}$; 3500- $4600 \mathrm{~m}$.

SINANPE: PNH

Herbarios peruanos: MOL (isotipo), USM (isotipo+16).

Observaciones: Hierba terrestre, conocida de algo más de cinco localidades, habitando pajonales paramunos y matormales de puna. Ha sido recolectada en las partes altas delas cuencas del Santay del Marañón. Sus poblaciones podrían estar afectadas por incendios intencionales.

\section{Gentianella vaginalis (Grisebach) J. Pringle$$
\text { EN, Blab(iii) }
$$

Publicación: Sida 11(4): 368. 1986.

Colección tipo: A. Cruckshanks s.n.

Herbarios: K.

Nombre común: D esconocido.

Registro departamental: JU, LI, PA.

Regiones Ecológicas: PSH, AA; 4500 m.

SINANPE: Sin registro.

Herbarios peruanos: USM (3).

Observaciones: Hierba perenne, conocida de cuatro localidades altoandinas en el centro del país. Aparentemente no se conoce de colecciones recientes. El ejemplartipo fuerecolectado delos alrededores de Cerro de Pasco, en el siglo XIX. Posteriormente otras recolectas han registrado esta especie muy cerca de asientos mineros.

\section{Gentianella violacea (D. Don ex G. Don) Fabris}

\section{VU, Bla}

Publicación: Bol. Soc. Argent. Bot. 7(2): 89. 1958.

Colección tipo: H. Ruiz \& J. Pavón s.n.

Herbarios: BM, K, MA, P.

Nombre común: D esconocido.

Registro departamental: HU, LL, SM.

Regiones Ecológicas: PSH, PAR; 3600$3900 \mathrm{~m}$.

SINAN PE: PNRA

Herbarios penuanos: USM (6).

Observaciones: Hierba perenne, conocida de unas seis localidades en el norte y centro del país. Localmente, sus poblaciones están integradas por numerosos individuos que habitan pajonales con mal drenaje. Incendios intencionales afectan algunas de sus poblaciones.

\section{Gentianella weberbaueri (Gilg) Fabris}

\section{VU, B lab(iii)}

Publicación: Bol. Soc. Argent. Bot. 7(2): 93. 1958.

Colección tipo: A. Weberbauer 2939

Herbarios: B; MOL!, USM!.

Nombre común: Pukamakashka.

Registro departamental: AN.

Regiones Ecológicas: PSH, AA; 3900$5100 \mathrm{~m}$.

SINANPE: PNH
Herbarios peruanos: CPUN (5), MOL

(isotipo), USM (isotipo+19).

Observaciones: Hierba perenne, muy vistosa, conocida de varias localidades en la Cordillera Blanca y la de Huayhuash, donde localmente es una planta frecuente, ocupando matorrales ralos. Fuera de áreas protegidas, la amenaza a este tipo de ambientes proviene de los incendios intencionales.

\section{Halenia barbicaulis Gilg}

\section{DD}

Publicación: Bot. Jahrb. Syst. 54(2, Beibl. 118): 112. 1916.

Colección tipo: A. Mathews s.n.

Herbarios: G.

Nombre común: D esconocido.

Registro departamental: AM.

Regiones Ecológicas: Sin datos; altitud desconocida.

SINAN PE: Sin registro.

Herbarios peruanos: Ninguno.

Observaciones: Hierba anual, conocida aparentemente sólo de la colección tipo, una planta recolectada en el siglo XIX de procedencia exacta desconocida.

\section{Halenia bella Gilg}

\section{NT}

Publicación: Repert. Spec. Nov. Regni Veg. 2(16-17): 52. 1906.

Colección tipo: A. Weberbauer 2065

Herbarios: B; MOL!, USM!.

Nombre común: D esconocido.

Registro departamental: AM, CA, CU, JU, PA.

Regiones Ecológicas: PAR, MA, BMHM; 2900-3600 m.

SINANPE: PNM

Herbarios penuanos: MOL (isotipo), USM (isotipo+4).

Observaciones: Hierba perenne, conocida de varias localidades aisladas entre ellas, de Amazonas a Cusco. Esta especie habita áreas ecotonales entre pajonal y bosque. Probablemente su rango de distribución sea mayor que la registrada.

\section{Halenia killipii C.K. Allen}

\section{CR, B lab(iii)}

Publicación: Ann. Missouri Bot. Gard. 20(1): 187. 1933.

Colección tipo: E.P. Killip \& A.C. Smith 22087

Herbarios: NY, US.

Nombre común: D esconocido.

Registro departamental: JU.

Regiones Ecológicas: AA; $4700 \mathrm{~m}$.

SINANPE: Sin registro.

Herbarios peruanos: Ninguno.

Observaciones: Hierba perenne, conocida solamente de una localidad ubicada en la Cordillera de Huaytapallana, al este de Huancayo, esta Cordillera ha sido poco herborizada, menos aún las partes más altas cerca de los glaciares. Al igual que otras especies altoandinas, problemas previstos están asociados a cambios climáticos y ampliación de la minería. 


\section{Halenia mathewsii Gilg}

$$
\text { EN, Blab(iii) }
$$

Publicación: Bot. Jahrb. Syst. 54(2, Beibl. 118): 111. 1916

Colección tipo: A. Mathews 523

Herbarios: $\mathrm{K}$.

Nombre común: D esconocido.

Registro departamental: LI.

Regiones Ecológicas: MA, PSH; 4000 m.

SINANPE: Sin registro.

Herbarios peruanos: Ninguno.

Observaciones: Hierba, conocida aparentemente de unas cuatro localidades en las cuencas del Chillón y Rímac. Ambas cuencas están severamente afectadas por las actividades mineras y pastoreo intensivo. No ha vuelto a ser recolectada desde aproximadamente la década de 1940.

\section{Halenia phyteumoides Gilg}

DD

Publicación: Bot. Jahrb. Syst. 54(2, Beibl. 118): 112-113. 1916.

Colección tipo: E.B. Philippi s.n.

Herbarios: B?

Nombre común: D esconocido.

Registro departamental: JU.

Regiones Ecológicas: Sin datos; altitud desconocida.

SINANPE: Sin registro.

Herbarios peruanos: Ninguno.

Observaciones: Hierba conocida solamente de la colección tipo, sin datos exactos de localidad y de la población.

\section{Halenia pinifolia Ruiz \& Pav. ex G. Don}

\section{DD}

Publicación: Gen. Hist. 4: 177. 1838.

Colección tipo: H. Ruiz \& J. Pavón s.n.

Hemarios: MA?.

Nombre común: D esconocido.

Registro departamental: Sin datos.

Regiones Ecológicas: Sin datos; altitud desconocida.

SINANPE: Sin registro.

Herbarios peruanos: Ninguno.

Observaciones: Hierba conocida de la descripción original y de taxonomía incierta.

\section{Halenia spatulata Allen}

\section{EN, Blab(iii)}

Publicación: Ann. Missouri Bot. Gard. 20(1): 183-184. 1933.

Colección tipo: F.W. Pennell 13749

Herbarios: PH, NY, US.

Nombre común: D esconocido.

Registro departamental: CU.

Regiones Ecológicas: PSH; 3900-4000 m.

SINAN PE: Sin registro.

Hemarios peruanos: CUZ (1).

Observaciones: Hierba perenne, conocida de dos localidades en las cuencas del Yavero y del Urubamba. Aparentemente no ha vuelto a ser recolectada desde la década de 1940. Pastoreo intensivo e incendios intencionales podrían afectar sus poblaciones.

\section{Halenia stuebelii Gilg}

\section{LC}

Publicación: Bot. Jahrb. Syst. 54(2, Beibl. 118): 110-111. 1916

Colección tipo: A. Stübel $49 \mathrm{e}$

Hembarios: $B$.

Nombre común: Desconocido.

Registro departamental: AM, AN, CA, CU, LI, LL, PU.

Regiones Ecológicas: PSH, PAR; 2200$4300 \mathrm{~m}$

SINANPE: PNH

Herbarios penuanos: CUZ (4), USM (4).

Observaciones: Hierba de amplia distribución; conocida de pajonales intervenidos y matorrales en campos de cultivo abandonados o lugares pedregosos.

\section{Halenia weberbaueri Allen}

\section{CR, B 1ab(iii)}

Publicación: Ann. Missouri Bot. Gard. 20(1): 189-190. 1933.

Colección tipo: A. Weberbauer 7498

Hemarios: $F$.

Nombre común: D esconocido.

Registro departamental: $\mathrm{AY}$.

Regiones Ecológicas: AA; 4300- $4500 \mathrm{~m}$.

SINANPE: Sin registro.

Herbarios peruanos: Ninguno.

Observaciones: Hierba altoandina, conocida aparentemente sólo de la descripción original, de una planta recolectada en la década de 1920, en una subcuenca del Mantaro. La localidad original, Razuhuillca, no ha sido herborizada desde entonces. Podría estar afectada por incendios intencionales y pastoreo intensivo.

\section{Lehmanniella huanucensis Simonis}

\section{CR, Bla}

Publicación: Proc. Kon. Ned. Akad. Wetensch., C 88(4): 411. 1985.

Colección tipo: F. Wolfe 12303

Herbarios: F, MO, NA; USM.

Nombre común: Desconocido.

Registro departamental: HU.

Regiones Ecológicas: BMHP; $1290 \mathrm{~m}$.

SINAN PE: RCS

Hemanios penuanos: USM (isotipo citado).

Observaciones: Arbusto conocido solamente de la localidad tipo, ubicada en la Reserva Comunal El Sira, en la cuenca del Pachitea. Esta especie fue recolectada en $1969 \mathrm{y}$ aparentemente no se conocen colecciones adicionales. Habita ambientes abiertos y probablemente modificados.

\section{Macrocarpaea angustifolia J.S. Pringle}

\section{DD}

Publicación: Novon 12(1): 80-81, f. 1. 2002.

Colección tipo: R.B. Foster et al. 7747

Herbarios: MO; USM.

Nombre común: D esconocido.

Registro departamental: PA.

Regiones Ecológicas: BMHM; $1900 \mathrm{~m}$. SINANPE: PNYC

Hembarios penuanos: USM (isotipo citado). 
Observaciones: Arbusto conocido de una población, en la cuenca del Pozuzo, registrada en 1984.

\section{Macrocarpaea canoefolia J.R. Grant}

$$
\text { VU, Bla }
$$

Publicación: Harvard Pap. Bot. 9(1): 2123, f. 2, 6 A-B. 2004.

Colección tipo: F. Woytkowski 35417

Herbarios: F, UC.

Nombre común: D esconocido.

Registro departamental: JU.

Regiones Ecológicas: BMHM, BMHP; 1420- $2000 \mathrm{~m}$.

SINAN PE: Sin registro.

Herbarios peruanos: USM?

Observaciones: Arbusto, descrito de una planta recolectada en 1948, de la cuenca del Tulumayo y conocido aparentemente de unas pocas localidades, todas en el valle de Chanchamayo.

\section{Macrocapaea chthonotropa J.R. Grant}

\section{NE}

Publicación: Harvard Pap. Bot. 9(2): 337-338, f. 14F-H. 2005.

Colección tipo: V. Quipuscoa et al. 2044

Hembarios: F; HUT!.

Nombre común: D esconocido.

Registro departamental: AM, SM.

Regiones Ecológicas: BMHP; 1440$2200 \mathrm{~m}$.

SINAN PE: Sin registro.

Hemarios penuanos: HUT (isotipo), USM (2).

Observaciones: Arbusto trepador, conocido del nor-oriente del país. La localidad original es una zona con poca herborización y fuerte presión de deforestación. O tras localidades están ubicadas en la cuenca del Utcubamba.

\section{Macrocarpaea corymbosa (Ruiz \& Pav.) E wan}

Publicación: Contr. U.S. Natl. Herb. 29(5): 242. 1948.

Colección tipo: H. Ruiz \& J. Pavón s.n.

Herbarios: MA.

Nombre común: Desconocido.

Registro departamental: CU, HU.

Regiones Ecológicas: BMHM; altitud desconocida.

SINAN PE: Sin registro.

Herbarios peruanos: Ninguno.

Observaciones: Este taxón fue considerado por Brako \& Zarucchi (1993) como un endemismo; sin embargo, no ha sido posible evaluarlo, ni asignarle una categoría.

\section{Macrocarpaea dillonii J.R. Grant}

Publicación: Harvard Pap. Bot. 9(1): 23, f. 1, 7 J-K. 2004.

Colección tipo: I. Sánchez V. et al. 9572

Herbarios: F, MO, NEU, U; CPUN!, HAO.

Nombre común: D esconocido.

Registro departamental: AM.

Regiones Ecológicas: BMHM; $1525 \mathrm{~m}$.

SINANPE: Sin registro.

Herbarios peruanos: CPUN (isotipo), HAO (isotipo citado).
Observaciones: Este taxón fue descrito posterior a Brako \& Zarucchi (1993); no ha sido posible evaluarlo, ni asignarle una categoná.

\section{Macrocarpaea ericii J.R. Grant}

\section{NE}

Publicación: Harvard Pap. Bot. 9(1): 2325, f. 1, 7 E-I. 2004.

Colección tipo: J. Campos et al. 4296

Herbarios: MO; $\underline{\mathrm{HUT}}$.

Nombre común: D esconocido.

Registro departamental: CA, PI.

Regiones Ecológicas: BMHM; 1600$2300 \mathrm{~m}$.

SINAN PE: Sin registro.

Hemarios penuanos: HUT (isotipo), USM (2).

Observaciones: Esta especie leñosa es conocida de la cuenca del Chinchipe. Habita ambientes ecotonales bosque-pajonal en suelos mal drenados. Podría estar representada en la flora ecuatoriana.

77. Macrocarpaea fotisiana J.R. Grant

Publicación: Harvard Pap. Bot. 9(1): 25, 27, f. 8C-E. 2004.

Colección tipo: R.D. Metcalf 30629

Herbarios: G, GH, MO, UC, US.

Nombre común: Campanilla.

Registro departamental: PU.

Regiones Ecológicas: BMHP; $1000-$ $1550 \mathrm{~m}$.

SINANPE: Sin registro.

Herbarios peruanos: Ninguno.

Observaciones: Este taxón fue descrito posterior a Brako \& Zarucchi (1993); no ha sido posible evaluarlo, ni asignarle una categońa.

\section{Macrocarpaea gran-pajatenaJ.R. Grant}

\section{NE}

Publicación: Harvard Pap. Bot. 9(2): 338-339, f. 14 I-K. 2005.

Colección tipo: K.R. Young \& B. León 4977

Herbarios: U; HUT!.

Nombre común: D esconocido.

Registro departamental: SM.

Regiones Ecológicas: BMHM; 2600$2750 \mathrm{~m}$.

SINANPE: PNRA

Herbarios peruanos: HUT (isotipo+3).

Observaciones: Planta leñosa, conocida solamente de unas pocas poblaciones en la cuenca del Montecristo, un tributario del Huallaga. Todas las localidades conocidas están en el Parque Nacional Río Abiseo.

\section{Macrocarpaea guttifera E wan}

\section{CR, Bla}

Publicación: Contr. U.S. Natl. Herb. 29(5): 237-238. 1948.

Colección tipo: E.P. Killip \& A.C. Smith 27045

Herbarios: US.

Nombre común: D esconocido.

Registro departamental: LO.

Regiones Ecológicas: $\mathrm{BHA} ; 100 \mathrm{~m}$.

SINANPE: Sin registro.

Herbarios peruanos: Ninguno. 
Observaciones: Arbusto, conocido aparentemente sólo de la colección tipo, una planta recolectada en 1929, de los alrededores de la ciudad de Iquitos.

\section{Macrocarpaea jalcaJ.R. Grant}

$$
\text { EN, B 1ab(iii) }
$$

Publicación: Harvard Pap. Bot. 9(1): 2931, f. 1, 10 A-C. 2004.

Colección tipo: H.E. Stork \& O.B. Horton 10118

Herbarios: F, K, UC, US.

Nombre común: D esconocido.

Registro departamental: CA.

Regiones Ecológicas: PAR, BPM; 2400$3200 \mathrm{~m}$.

SINANPE: PNC

Herbarios peruanos: USM (4).

Observaciones: Árbol, de hasta $20 \mathrm{~m}$ de alto, conocido de la cuenca del Chotano, ocupando ambientes ecotonales entre lajalca y el bosque pluvial. Si bien es conocida de un área protegida, la deforestación podría considerarse una amenaza a esta especie.

\section{Macrocarpaea kayakifoliaJ.R. Grant}

$$
\text { CR, Bla }
$$

Publicación: Harvard Pap. Bot. 9(1): 3132, f. 3, 3 C-D. 2004.

Colección tipo: B. Stein et al. 3864

Hemarios: MO, NEU, NY, U; USM.

Nombre común: D esconocido.

Registro departamental: HU.

Regiones Ecológicas: BMHM; 2250$2450 \mathrm{~m}$.

SINANPE: Sin registro.

Herbarios penuanos: USM (isotipo).

Observaciones: Árbol. conocido de una sola colección proveniente, de la cuenca alta del Huallaga. La localidad tipo, Carpish, es conocida por la riqueza de sus especies, pero sus ambientes naturales están siendo intervenidos por la deforestación.

\section{Macrocarpaea kuelapJ.R. Grant}

$$
\text { EN, B 1ab(iii) }
$$

Publicación: Harvard Pap. Bot. 9(1): 3234, f. 1, 10 D-G. 2004.

Colección tipo: P.C. Hutchison \& J.K. Wright 3903

Hembarios: F, K, MO, NY, UC, US; USM. Nombre común: D esconocido.

Registro departamental: AM, CA.

Regiones Ecológicas: BMHM; 2160$2550 \mathrm{~m}$.

SINAN PE: Sin registro.

Herbarios peruanos: HAO (2), USM (isotipo citado).

Observaciones: Árbol o arbusto conocido de dos poblaciones disyuntas, una en la vertiente oriental (Chachapoyas) y la otra en la del Pacífico (Huambos). Amenazas a sus poblaciones están asociadas a la deforestación, en especial de los bosques fragmentados del noroccidente del país.
83. Macrocarpaea kuepfeniana J.R. Grant

$$
\text { CR, B lab(iii) }
$$

Publicación: Harvard Pap. Bot. 9(1): 34, f. 2, 8 A-B. 2004

Colección tipo: C. Vargas C. 18928

Hemarios: ; CUZ!

Nombre común: D esconocido.

Registro departamental: PU.

Regiones Ecológicas: BMHP; 950—1100 m. SINANPE: Sin registro.

Herbarios peruanos: CUZ (holotipo).

Observaciones: Arbusto conocido de la colección tipo, una planta recolectada en la cuenca del San Gabán, en 1967. Esta cuenca viene siendo transformada por la ampliación de la actividad agrícola y por planes de desarrollo asociados a carreteras e hidroeléctricas.

\section{Macrocarpaea loranthoides (Griseb.) Maas}

\section{DD}

Publicación: Monogr. Syst. Bot. Missouri Bot. Gard. 45:1256. 1993.

Colección tipo: A. Mathews 1315

Herbarios: OXF

Nombre común: D esconocido.

Registro departamental: AM.

Regiones Ecológicas: Sin datos; altitud desconocida.

SINAN PE: Sin registro.

Herbarios peruanos: Ninguno.

Observaciones: Arbusto aparentemente conocido sólo dela cuenca del Marañón. Al parecer, no ha vuelto a ser recolectada desde la década de 1930. Se desconoce la situación de sus poblaciones.

\section{Macrocarpaea luya J.R. Grant}

$$
\text { CR, B 1ab(iii) }
$$

Publicación: Harvard Pap. Bot. 9(1): 3435, f. 1, 9 A-B. 2004.

Colección tipo: C. Díaz \& J. Campos 3786

Henbarios: MO; USM!.

Nombre común: D esconocido.

Registro departamental: AM.

Regiones Ecológicas: BPM; $3310 \mathrm{~m}$.

SINAN PE: Sin registro.

Herbarios penuanos: USM (holotipo).

Observaciones: Arbusto conocido aparentemente sólo de la colección tipo, una planta recolectada en 1989, de los fragmentos de bosque en la cuenca del Utcubamba.

\section{Macrocarpaea maguirei R.E. Weaver\& J.R. Grant}

$$
\text { EN, B1a }
$$

Publicación: Harvard Pap. Bot. 8(1): 95, 97-98, f. 1, 8. 2003.

Colección tipo: B. Maguire \& C.E. Maguire 61569

Hemanios: GH, NY.

Nombre común: D esconocido.

Registro departamental: CU.

Regiones Ecológicas: BMHM; 2800$3150 \mathrm{~m}$.

SINAN PE: PNM

Herbarios peruanos: USM (3). 
Observaciones: Esta especie arbórea se conoce de bosques húmedos ecotonales. Todas las colecciones provienen de un área protegida, Parque Nacional Manu, las que fueron recolectadas entre 1952 y 2000.

\section{Macrocarpaea normaeJ.R. Grant}

$$
\text { EN, Bla }
$$

Publicación: Harvard Pap. Bot. 9(1): 3536, f. 2, 10 H-J. 2004.

Colección tipo: A. Weberbauer 7921

Herbarios: F, GH, NY, US.

Nombre común: D esconocido.

Registro departamental: CU.

Regiones Ecológicas: BMHM; 1835$2800 \mathrm{~m}$.

SINANPE: PNM

Herbarios penuanos: CUZ (4).

Observaciones: Arbusto conocido solamente del sur del país. El ejemplar tipo proviene de la cuenca del Yanatili. O tras poblaciones conocidas están ubicadas en otros tributarios del Urubamba.

\section{Macrocarpaea obnubilataJ.R. Grant}

\section{CR, Bla}

Publicación: Harvard Pap. Bot. 9(1): 36, f. 2, 6 G-H. 2004.

Colección tipo: C. Díaz \& S. Baldeón 2256

Herbarios: MO, NEU, NY, U; USM!.

Nombre común: D esconocido.

Registro departamental: HU.

Regiones Ecológicas: BMHM; altitud desconocida.

SINANPE: Sin registro.

Herbarios penuanos: USM (isotipo).

Observaciones: Arbusto conocido aparentemente de la colección tipo, una planta recolectada en 1987 de la cuenca del Huallaga. La localidad tipo, Carpish, alberga otros endemismos y debería ser de interés para la conservación.

\section{Macrocarpaea ostentans J.R. Grant}

\section{EN, Bla}

Publicación: Harvard Pap. Bot. 9(1): 3637, f. 2, 7 C-D. 2004.

Colección tipo: D.N. Smith et al. 6440

Herbarios: MO, U; USM!.

Nombre común: D esconocido.

Registro departamental: HU, PA.

Regiones Ecológicas: BMHM, BMHP; $1080-1700 \mathrm{~m}$.

SINAN PE: RCS

Herbarios penuanos: USM (isotipo).

Observaciones: Arbusto, conocido originalmente de la cuenca del Palcazú, así como del Pachitea. Probablemente, la deforestación de los bosques montanos sea la amenaza más importante.

\section{Macrocarpaea pachystyla Gilg}

DD

Publicación: Bot. Jahrb. Syst. 22(2): 336. 1896. Colección tipo: J. Tafalla s.n.

Herbarios: G, MA-Ruiz \& Pavón.

Nombre común: Desconocido.

Registro departamental: HU, JU, PU, SM.

Regiones Ecológicas: BMHP; altitud desconocida.

SINANPE: Sin registro.

Herbarios peruanos: Ninguno.

Observaciones: Arbusto, conocido de varias localidades, del centro y sur del país, en las cuencas del Huallaga, Tulumayo e Inambari. Se desconoce el estado de sus poblaciones

\section{Macrocarpaea pajonalisJ.R. Grant}

$$
\text { VU, Bla }
$$

Publicación: Harvard Pap. Bot. 9(1): 3840, f. 2, 11 G-K. 2004.

Colección tipo: B. Stein \& C. Todzia 2322

Herbarios: MO, NY, US; USM.

Nombre común: D esconocido.

Registro departamental: HU, PA.

Regiones Ecológicas: $\mathrm{BPM}, \mathrm{BMHM}$; 2450-3000 m.

SINANPE: PNYC

Herbarios penuanos: USM (isotipo+3).

Observaciones: Arbusto conocido de varias colecciones realizadas en las cuencas del Huallaga y Perené. La localidad original está ubicada en Carpsih, la cual alberga otros endemismos, pero con problemas de deforestación.

\section{Macrocappaea quechua J.R. Grant}

\section{DD}

Publicación: Harvard Pap. Bot. 9(2): 339, 341, f. 14 A-E. 2005.

Colección tipo: J. Schunke V. 6280

Herbarios: GH, MG, NY, U.

Nombre común: D esconocido.

Registro departamental: SM.

Regiones Ecológicas: BMHM, BMHP; 800- $1900 \mathrm{~m}$.

SINAN PE: Sin registro.

Herbarios peruanos: AMAZ (1), USM (1).

Observaciones: Planta perenne conocida de varias localidades en las cuencas del Huallaga y del Mayo.

\section{Macrocarpaea robin-fosteriJ.R. Grant}

$$
\text { EN, Bla }
$$

Publicación: Harvard Pap. Bot. 9(1): 4041, f. 2, 11 L-O. 2004.

Colección tipo: R.B. Foster 9114

Herbarios: MO, NY; USM.

Nombre común: D esconocido.

Registro departamental: PA.

Regiones Ecológicas: BMHM, BMHP; 500- $2500 \mathrm{~m}$.

SINAN PE: PNYC

Hembarios peruanos: USM (isotipo+4). 
Observaciones: Este arbusto o árbol pequeño se conoce solamente de las cimas de bosques húmedos montanos de Pasco, incluyendo los del Parque Nacional Yanachaga-Chemillén.

\section{Macrocarpaea tabula-fluctivagifoliaJ.R. Grant}

$$
\text { EN, Bla }
$$

Publicación: Harvard Pap. Bot. 9(1): 4142, f. 2, 9 E-F. 2004.

Colección tipo: F. Wolfe 12333

Herbarios: F, NA, NY; USM.

Nombre común: D esconocido.

Registro departamental: HU.

Regiones Ecológicas: BMHM, BMHP;

1290- $2000 \mathrm{~m}$.

SINAN PE: RCS

Hembarios penuanos: USM (isotipo citado).

Observaciones: Planta leñosa escandente conocida de los límites de la Zona Reservada El Sira, en la cuenca del Pachitea. Habita márgenes de bosque 0 en lugares expuestos.

\section{Macrocarpaea tahuantinsuyuana J.R. Grant}

$$
\text { EN, Bla }
$$

Publicación: Harvard Pap. Bot. 9(1): 42, f. 2, 6 C-F. 2004.

Colección tipo: D.N. Smith et al. 6282

Herbarios: MO, NEU, NY, US; USM.

Nombre común: D esconocido.

Registro departamental: JU, PA.

Regiones Ecológicas: BMHM; 1600$1920 \mathrm{~m}$.

SINAN PE: Sin registro.

Herbarios penuanos: USM (isotipo citado).

Observaciones: Arbusto escandente conocido del centro del país, de la cuenca del Perené. Esta especie ocupa ecotonos bosquepajonal en las vertientes húmedas orientales.

\section{Macrocarpaea viscosa (Ruiz \& Pav.) Gilg EN, Blab(iii)}

Publicación: Bot. Jahrb. Syst. 22(2): 337. 1896. Colección tipo: H. Ruiz \& J. Pavón s.n.

Herbarios: MA-Ruiz \& Pavón.

Nombre común: D esconocido.

Registro departamental: HU, JU, PA.

Regiones Ecológicas: BMHM?; $2824 \mathrm{~m}$.

SINAN PE: Sin registro.

Herbarios penuanos: USM?.

Observaciones: Arbusto conocido de las cuencas del Perené y Huallaga. Grant (2003) nota que esta especie fue recolectada después de un lapso de casi 200 años, aunque Macbride (1959) señala su presencia en Junín de una planta recolectada en 1922.

\section{Macrocarpaea wallnoeferi J.R. Grant}

$$
\text { EN, Bla }
$$

Publicación: Harvard Pap. Bot. 9(1): 4244, f. 2, 10 K-N. 2004.

Colección tipo: B. Wallnöfer 18-20388

Herbarios: U, WU.

Nombre común: D esconocido.

Registro departamental: HU, JU, PA.

Regiones Ecológicas: BMHP; 800-1200 m.

SINAN PE: RCS

Herbarios peruanos: AMAZ (1), USM (1)?.
Observaciones: Arbusto o árbol, conocido de los bosques húmedos premontanos de Huánuco a Junín, en por lo menos tres subpoblaciones; la presente en la Reserva Comunal El Sira, cuenca del Pachitea, es la mejor representada en los herbarios. Podría también estar representada en el Parque Nacional YanachagaChemillén.

\section{Macrocarpaea weigendionum J.R. Grant}

\section{DD}

Publicación: Harvard Pap. Bot. 9(1): 44, f. 2, 11 A-F. 2004.

Colección tipo: M. Weigend et al. 5363

Herbarios: B, F, NY, U, US; $\underline{\mathrm{HUT}}$.

Nombre común: D esconocido.

Registro departamental: HU, UC.

Regiones Ecológicas: $\mathrm{BMHP}, \mathrm{BHA}$; 170-930 m.

SINAN PE: Sin registro.

Herbarios peruanos: HUT (isotipo citado).

Observaciones: Este arbusto se conoce de cerca de los límites sur del Parque Nacional Cordillera Azul. Probablemente con mayor exploración de esa cordillera pueda conocerse el tamaño y características de sus poblaciones.

\section{Macrocarpaea wurdackii R.E. Weaver\& J.R. Grant

$$
\text { EN, Blab(iii) }
$$

Publicación: Harvard Pap. Bot. 8(1): 98100, f. 1, 9. 2003.

Colección tipo: J.J. Wurdack 1071

Herbarios: NY, US; USM.

Nombre común: D esconocido.

Registro departamental: AM, SM.

Regiones Ecológicas: PAR, BMHM; 1850- $2400 \mathrm{~m}$.

SINAN PE: Sin registro.

Herbarios peruanos: AMAZ (1), USM (isotipo +2).

Observaciones: Arbusto de flores amarillas, conocido de colecciones realizadas a mediados de los 1980. Se considera localmente raray parece ocupar ambientes ecotonales entre pajonales y bosque. Las localidades de las que se conoce están siendo sujetas a deforestación, especialmente en la provincia de Rioja, la cual es también conocida por albergar poblaciones de la especie en peligro Lagthix flavicauda 0 «mono choro de cola amarilla».

100. Macrocarpaea xerantifulva J.R. Grant

$$
\begin{aligned}
& \text { NE } \\
& \text { Publicación: Harvard Pap. Bot. 9(2): 341, } \\
& \text { f. } 6 \text { C-G. 2005. } \\
& \text { Colección tipo: J. Campos \& Z. García } \\
& 3960 \\
& \text { Herbarios: MO, U. } \\
& \text { Nombre común: Desconocido. } \\
& \text { Registro departamental: CA, PI. } \\
& \text { Regiones Ecológicas: BMHM; 1700- } \\
& \text { 2300 m. } \\
& \text { SINANPE: Sin registro. } \\
& \text { Herbarios penuanos: USM (isotipo)?. }
\end{aligned}
$$

Observaciones: Arbusto conocido del nor-oriente del país. Esta especie fue descrita de una planta recolectada en 1997, en la cuenca del Tabaconas. Otras poblaciones conocidas provienen de las cuencas del Chamaya, Chotano y Huancabamba. Una población existe cerca al Parque Nacional de Cutervo. 
101. Macrocarpaea zophoflora R.E. Weaver\& J.R. Grant

\section{DD}

Publicación: Harvard Pap. Bot. 8(1): 100-102, f. 1, 10-11. 2003.

Colección tipo: J.J. Wurdack 1618

Herbarios: F, GH, K, NY, P, S, UC, US; USM.

Nombre común: Tabaco caspi.

Registro departamental: AM.

Regiones Ecológicas: BMHM; 2700$3100 \mathrm{~m}$.

SINAN PE: Sin registro.

Herbarios peruanos: USM (isotipo citado).

Observaciones: Arbusto conocido de un bosque achaparrado en la cima de la cordillera en Amazonas.

\section{Potalia yanamonoensis Struwe \& V. Albert}

\section{NE}

Publicación: Syst. Bot. 29(3): 693-694, f. 10 k-m. 2004.

Colección tipo: R. Vásquez et al. 5132

Herbarios: MO, NY.

Nombre común: D esconocido.

Registro departamental: LO.

Regiones Ecológicas: BHA; $106 \mathrm{~m}$.

SINAN PE: Sin registro.

Herbarios peruanos: Ninguno.

Observaciones: Esta especie arbustiva es morfológicamente muy cercana a Pdalia resinifea, de la que se diferencia por detalles de los frutos. Se conoce solamente de una localidad dentro de una reserva turística en la cuenca del río Napo. Se la deja sin evaluar esperando que nuevas recolectas contribuyan al conocimiento de esta especie recientemente descrita.
103. Tachia loretensis Maguire \& Weaver

VU, B1a

Publicación: J. Arnold Arbor. 56(1): 117, f. 7. 1975 .

Colección tipo: E.P. Killip \& A.C. Smith 29925

Hemarios: F, NY, US.

Nombre común: D esconocido.

Registro departamental: LO.

Regiones Ecológicas: BHA; 90-130 m. SINANPE: RNAM

H erbarios peruanos: AMAZ (3), USM (3)?.

Observaciones: Arbusto, conocido de varias localidades dispersas en el centro de la Amazonía peruana. Por lo menos, dos de sus poblaciones reciben algún tipo de protección. 


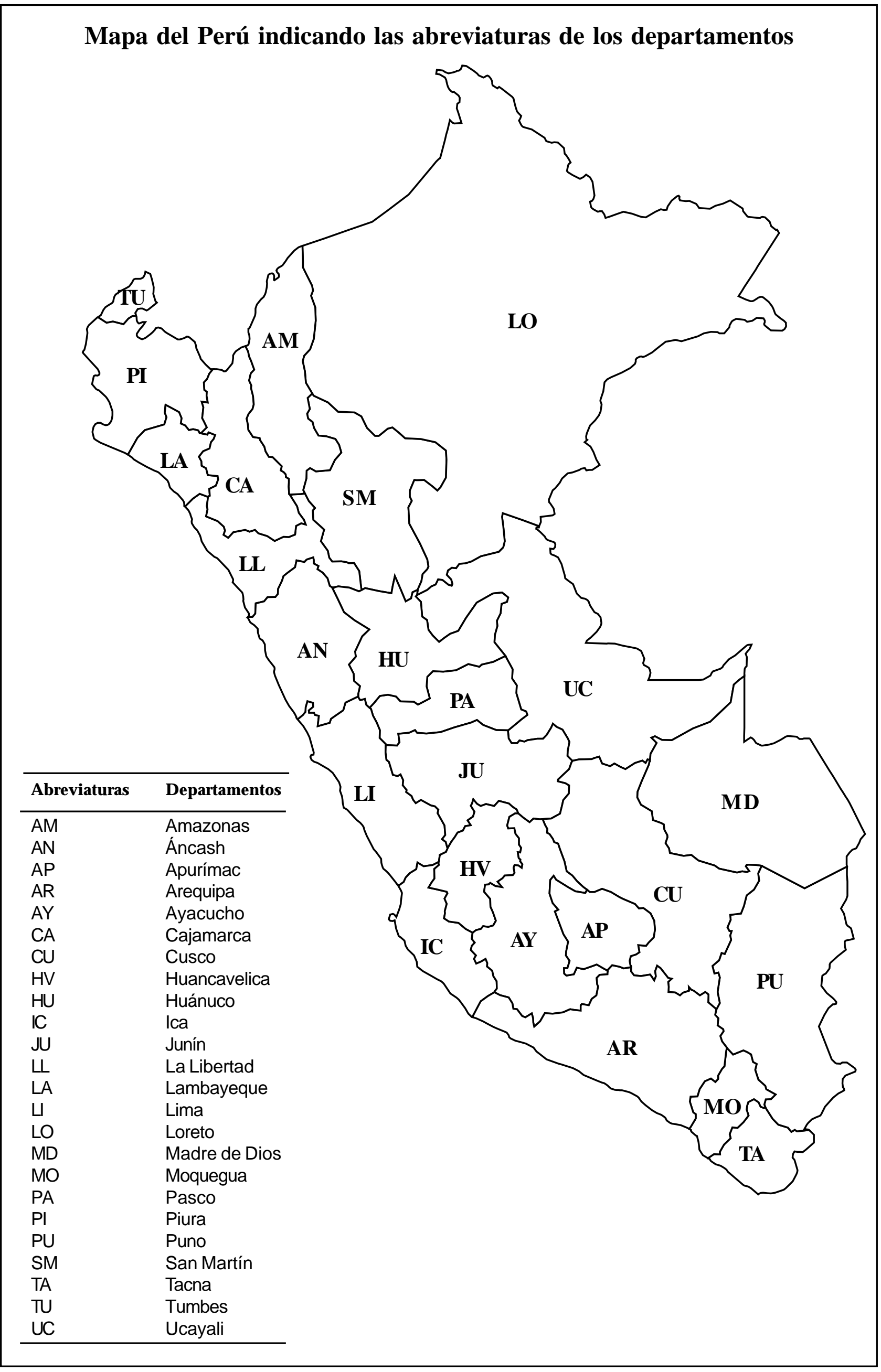

